\title{
Correction to: Impact of reducing the duration of antibiotic treatment on the long-term prognosis of community acquired pneumonia
}

\author{
Ane Uranga ${ }^{1 *}$, Amaia Artaraz ${ }^{1}$, Amaia Bilbao ${ }^{2,3,4}$, Jose María Quintana ${ }^{3,4,5}$, Ignacio Arriaga ${ }^{6}$, Maider Intxausti ${ }^{6}$,
} Jose Luis Lobo ${ }^{7}$, Julia Amaranta García7, Jesus Camino ${ }^{8}$ and Pedro Pablo España ${ }^{1}$

\section{Correction to: BMC Pulm Med 20, 261 (2020)} https://doi.org/10.1186/s12890-020-01293-6 Following publication of the original article [1], the authors flagged that their article had published with 'MD' erroneously included in the names of all the authors.

This has since been corrected in the published article and the corrected names may be found in this correction.

The publisher apologizes for any inconvenience caused.

\section{Author details}

1 'Department of Pneumology, Osakidetza, Universitary Hospital of GaldakaoUsansolo, Barrio Labeaga s/n, 48960 Galdakao, Bizkaia, Spain. ${ }^{2}$ Research Unit, Osakidetza, Universitary Hospital of Basurto, Bilbao, Bizkaia, Spain. ${ }^{3}$ Health Services Research on Chronic Patients Network (REDISSEC), Galdakao, Bizkaia
Spain. ${ }^{4}$ Institute of Research in Health Services Kronikgune, Barakaldo, Bizkaia, Spain. ${ }^{5}$ Research Unit, Osakidetza, Universitary Hospital of Galdakao-Usansolo, Galdakao, Bizkaia, Spain. ${ }^{6}$ Department of Pneumology, Osakidetza, Universitary Hospital of Basurto, Bilbao, Bizkaia, Spain. ${ }^{7}$ Department of Pneumology, Osakidetza, Universitary Hospital of Alava, Vitoria, Alava, Spain. ${ }^{8}$ Department of Pneumology, Osakidetza, Hospital of San Eloy, Barakaldo, Bizkaia, Spain.

Published online: 11 January 2021

\section{Reference}

1. Uranga A, Artaraz A, Bilbao A et al. Impact of reducing the duration of antibiotic treatment on the long-term prognosis of community acquired pneumonia. BMC Pulm Med. 2020;20:261. https://doi.org/10.1186/s1289 0-020-01293-6. 